\title{
Nucleation and growth of Si nanowires from silicon oxide
}

\author{
N. Wang, Y. H. Tang, Y. F. Zhang, C. S. Lee, and S. T. Lee* \\ Center of Super-Diamond and Advanced Films, Department of Physics and Materials Science, The City University of Hong Kong, \\ Hong Kong, China
}

(Received 18 August 1998; revised manuscript received 28 September 1998)

\begin{abstract}
Nucleation and growth of Si nanowires by laser ablation and thermal evaporation of Si powder sources mixed with $\mathrm{SiO}_{2}$ have been investigated by means of transmission electron microscopy. At the initial nucleation stage, $\mathrm{Si}$ oxide vapor condensed on the substrate and formed Si nanoparticles (the nuclei of nanowires). Each Si nanowire nucleus consisted of a polycrystalline Si core containing a high density of defects and a Si oxide shell. A growth mechanism was proposed based on the microstructure and different morphologies of the Si nanowires observed. [S0163-1829(98)51348-3]
\end{abstract}

The synthesis of one-dimensional nanostructures is a challenge in materials science. Since the successful growth of $\mathrm{Si}$ whiskers by the vapor-liquid-solid (VLS) reaction, ${ }^{1,2}$ many efforts have been made to synthesize Si nanowires by employing different methods, such as photolithography technique combined with etching ${ }^{3-5}$ and scanning tunneling microscopy. ${ }^{6,7}$ Recently, Si nanowires have been successfully synthesized by a different method, namely, the laser ablation of metal-containing $\mathrm{Si}$ targets. $^{8-11}$ Previous investigations ${ }^{8,9}$ showed that metal or metal-silicide nanoparticles acted as the critical catalyst during the synthesis assisted by laser ablation. Therefore, a growth mechanism of $\mathrm{Si}$ nanowires has been extrapolated from the VLS reaction. ${ }^{8,9}$ However, a different model has been proposed which is supported by the fact that metal catalysts are not necessary during synthesis by laser ablation. ${ }^{12} \mathrm{SiO}_{2}$ was discovered to be the special and effective catalyst which largely enhances $\mathrm{Si}$ nanowire growth (see Table I). Moreover, structural investigations show that high-density defects and silicon oxide outer layers may play an important role for $\mathrm{Si}$ nanowire growth. ${ }^{12}$ In this paper, we report the synthesis of Si nanowires by laser ablation and thermal evaporation of highly pure $\mathrm{Si}$ powder mixed with $\mathrm{SiO}_{2}$. Included are observations of the microstructure and growth morphology of Si nanowire nuclei by transmission electron microscopy (TEM) and a discussion of the growth mechanisms.

The Si nanowires investigated in this work have been synthesized by laser ablation ${ }^{10,11}$ and thermal evaporation in an evacuated quartz tube containing $\mathrm{Ar}$ gas (500 Torr). The growth rate of Si nanowires was higher with the assistance of laser ablation than with thermal evaporation alone. Si nanowires synthesized by both methods had the same morphology. The solid source was highly pure Si powder mixed with approximately $70 \mathrm{wt} \% \mathrm{SiO}_{2}$ (all materials from Goodfellow, purity $99.99 \%$ ). The temperatures around the source and the area of the quartz tube where the nanowires grew were about $1200{ }^{\circ} \mathrm{C}$ and $930{ }^{\circ} \mathrm{C}$, respectively. After $12 \mathrm{~h}$ of thermal evaporation, a Si nanowire product (spongelike, dark red in color) formed on the inside wall of the quartz tube. To collect the Si nanowire nuclei, a Mo grid was placed in the region of the quartz tube where the nanowires grew. Some $\mathrm{Si}$ nanowires nucleated and grew on the grid. Structural inves- tigation was carried out using a Philips CM200FEG transmission electron microscope working under $200 \mathrm{kV}$.

As demonstrated from the data in Table I the presence of $\mathrm{SiO}_{2}$ in the powder targets significantly enhances $\mathrm{Si}$ nanowire growth. The $\mathrm{Si}$ nanowire product obtained by using a powder target composed of $50 \% \mathrm{SiO}_{2}$ and $50 \% \mathrm{Si}$ is 30 times greater than the amount generated by using a metal containing target. In addition, very few $\mathrm{Si}$ nanowires form if $\mathrm{Si}$ single-crystal wafers or pure $\mathrm{Si}$ powder are used as targets. Since $\mathrm{SiO}_{2}$ is the dominant impurity in the two kinds of targets mentioned, it is believed that in this case, the limited amount of Si nanowire formation that does occur is also due to the presence of $\mathrm{SiO}_{2}$. Pure $\mathrm{SiO}_{2}$ powder can not produce Si nanowires.

A typical morphology of the as-grown $\mathrm{Si}$ nanowires is shown in the TEM image in Fig. 1, where two major forms can be seen. Si nanowires with uniform diameters and smooth surfaces are one major component, while the other kind, Si nanoparticles coexist with the nanowires. Most Si nanowires are extremely long $(>10 \mu \mathrm{m})$ and randomly oriented. It is interesting to note that most Si nanoparticles appear in the form of chain (as marked by the arrow). Short bars of amorphous silicon oxide connect these nanoparticles.

Figure 2(a) shows the initial nucleation stage of the $\mathrm{Si}$ nanowires on the Mo grid. Si nanoparticles formed first, as

TABLE I. Yields of Si nanowires for different experimental conditions.

\begin{tabular}{lcc}
\hline \hline $\begin{array}{l}\text { Target } \\
(\text { wt. \%) }\end{array}$ & $\begin{array}{c}\text { Furnace } \\
\text { temperature }\left({ }^{\circ} \mathrm{C}\right)\end{array}$ & $\begin{array}{c}\text { Yield } \\
(\mathrm{mg})\end{array}$ \\
\hline $\mathrm{Si}+1-3 \% \mathrm{Fe}$ & 1200 & $\sim 0.1$ \\
$\mathrm{Si}$ water & 1200 & Very few $<0.01$ \\
$\mathrm{Si}$ powder & 1200 & Very few $<0.01$ \\
$\mathrm{Si}+5 \% \mathrm{SiO}_{2}$ & 1200 & $\sim 0.3$ \\
$\mathrm{Si}+10 \% \mathrm{SiO}_{2}$ & 1200 & $\sim 0.5$ \\
$\mathrm{Si}+30 \% \mathrm{SiO}_{2}$ & 1200 & $\sim 2.5$ \\
$\mathrm{Si}+50 \% \mathrm{SiO}_{2}$ & 1200 & $\sim 3.0$ \\
$\mathrm{Si}+70 \% \mathrm{SiO}_{2}$ & 1200 & $\sim 2.5$ \\
$\mathrm{Si}+90 \% \mathrm{SiO}_{2}$ & 1200 & $\sim 0.5$ \\
$\mathrm{SiO}$ & $800-1200$ & 0 \\
\hline \hline
\end{tabular}




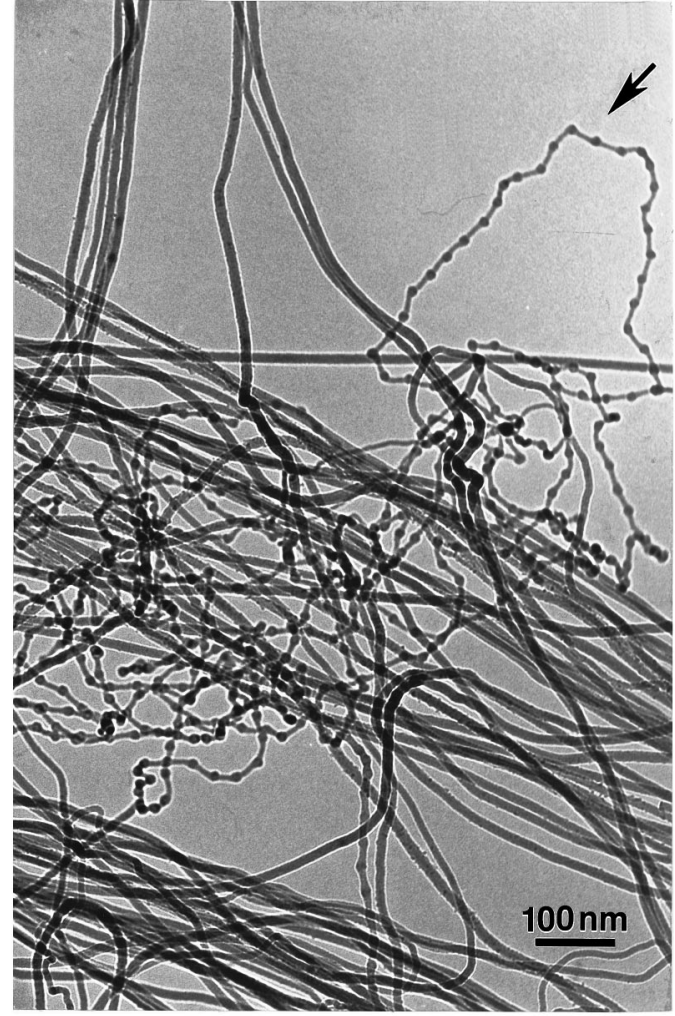

FIG. 1. TEM image showing two major morphologies of Si nanowires.

identified by electron diffraction and most piled up on the substrate. However, some particles (as marked by the arrow) stood alone from the others and grew fast since their preferable growth directions were normal to the surface of the substrate [see also Fig. 2(b)]. These preferable particles were indeed the nuclei of the nanowires. As revealed in Fig. 2(b), no obvious metal catalysts or impurities formed on the tip of the nucleus. The nucleus simply consisted of a Si crystalline core with a high density of defects and an amorphous outer layer. Since only silicon and oxygen were detected by electron energy dispersive spectrometer (EDS) in situ the microscope, the amorphous outer layer should be silicon oxide.

Because tip areas determine the one-dimensional growth phenomenon of Si nanowires, high-resolution transmission electron microscopy (HRTEM) was employed to investigate the microstructure of the tips. A typical Si nanowire tip is shown in the HRTEM image in Fig. 3(a). The tip is generally round and covered by a relatively thick amorphous layer. Because of this feature, under low magnification, a tip looked thicker than the nanowire itself. The contrast of the amorphous layer was quite uniform and only $\mathrm{Si}$ crystalline structure was observed within the tip. This is contrary to the nanowires grown by the VLS where metal drops were always formed on the tips. Similar to the microstructure of the nuclei, the Si crystal core in the nanowire tip contained a high density of stacking faults and micro-twins, which were along the axis of the nanowire in the [112] direction. These kinds of defects have been observed in most Si nanowires in our previous work. ${ }^{10}$

We believe that the amorphous silicon oxide was the key factor which significantly enhanced the nucleation and one-
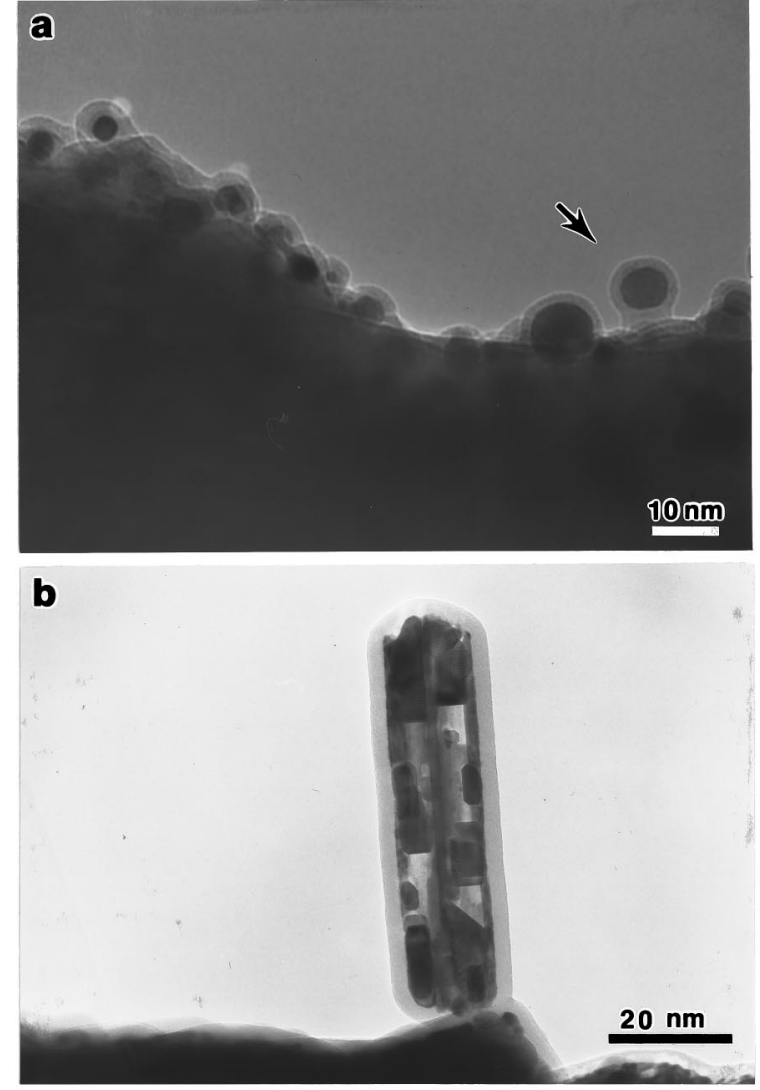

FIG. 2. (a) Si nanowire nuclei formed on the Mo grid and (b) initial growth stage of $\mathrm{Si}$ nanowire.

dimensional growth of the Si nanowires. The growth mechanism was different from that of the classic VLS growth of $\mathrm{Si}$ whiskers where $\mathrm{Si}$ vapor diffused into metal drops (e.g., $\mathrm{Au}$ ) and accumulated causing one-dimensional growth of $\mathrm{Si}$. In the present case, however, little $\mathrm{Si}$ vapor was generated under $1200^{\circ} \mathrm{C}$. This was evidenced by the fact that the material deposited on the water-cooled $\mathrm{Cu}$ finger surface was $\mathrm{Si}_{x} \mathrm{O}_{y}$ $(x=0.51, y=0.49)$ as determined by EDS. Since the vapor phase was quenched on the cooled finger, the chemical composition of the material did not change. This indicated that the vapor phase generated by thermal evaporation of the solid source $\left(\mathrm{Si}+\mathrm{SiO}_{2}\right)$ mainly consisted of $\mathrm{SiO}$. The formation of $\mathrm{SiO}$ was due to the reaction of $\mathrm{Si}$ and $\mathrm{SiO}_{2}$ since $\mathrm{SiO}$ is known to be an amorphous semiconductor of high resistivity that is easily generated from powder mixtures (especially in equimolar amounts of mixtures) of $\mathrm{Si}$ and $\mathrm{SiO}_{2}$ by heating. ${ }^{13,14}$ The nucleation of nanoparticles may involve different decompositions of the $\mathrm{Si}$ oxide vapor phase at a relatively low temperature of $930{ }^{\circ} \mathrm{C}$ as shown below:

$$
\begin{gathered}
\mathrm{Si}_{x} \mathrm{O} \rightarrow \mathrm{Si}_{x-1}+\mathrm{SiO}(x>1), \\
2 \mathrm{SiO} \rightarrow \mathrm{Si}+\mathrm{SiO}_{2} .
\end{gathered}
$$

These decompositions resulted in the precipitation of silicon nanoparticles (the nuclei of $\mathrm{Si}$ nanowires) surrounded by shells of silicon oxide as observed in Fig. 2(a). Such precipitation of $\mathrm{Si}$ nanoparticles from $\mathrm{SiO}$ by annealing has been quite well known since the $1950 \mathrm{~s} .{ }^{15}$ 

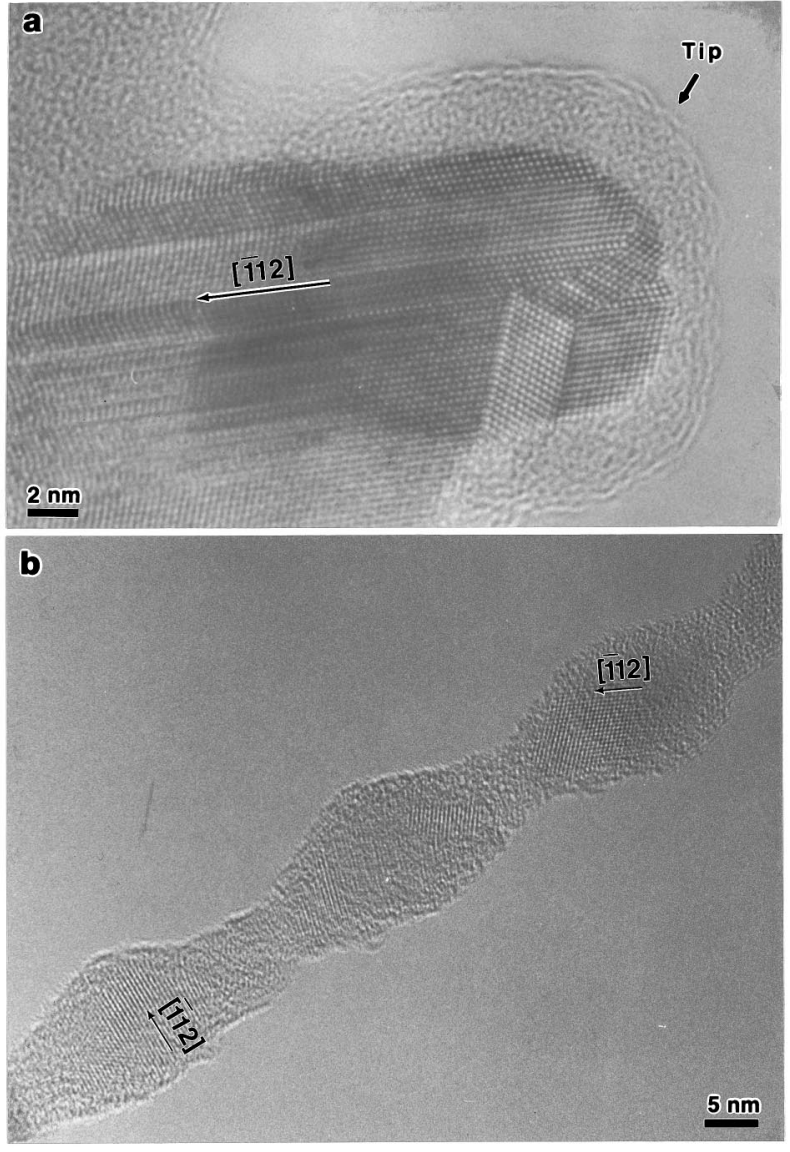

FIG. 3. HRTEM images of (a) Si nanowire tip and (b) Si nanoparticle chain.

The growth mechanism of Si nanowires is suggested to be determined by the following factors: (1) the catalytic effect of the relatively thick $\mathrm{Si}_{x} \mathrm{O}$ layer on nanowire tips; (2) the $\mathrm{SiO}_{2}$ (much more stable than $\mathrm{SiO}$ ) component in the shell, which is formed from the $\mathrm{SiO}$ decomposition and retards the lateral growth of nanowire; (3) the main defects in the $\mathrm{Si}$ nanowires, which are stacking faults (along the nanowire growth direction of $\langle 112\rangle$ ) and microtwins. The presence of these kinds of defects at the tip areas should result in the fast growth of Si nanowires; (4) the $\{111\}$ surface, which has the lowest surface energy among the Si surfaces, plays an important role during nanowire growth. Since surface energy is more important when the crystal size is reduced to nanometer scale, the presence of the $\{111\}$ surfaces parallel to the axes of the nanowires reduces the system energy. These important factors determine the growth direction of Si nanowires to be $\langle 112\rangle$.

According to the mechanism discussed above, nucleation and growth occurred at all times during evaporation since the $\mathrm{SiO}$ vapor phase was continually generated. Nuclei formed on nanowire tips with different crystalline orientations during growth. These unfavorable nuclei could not grow fast along the nanowire and would cause a change of growth direction or renucleation. Such renucleations resulted in the formation of nanoparticle chains (see Fig. 1) which coexisted with the nanowires. A HRTEM image taken from a Si nanoparticle chain supports this growth mechanism. As shown in Fig. 3(b), the Si particles in the chain have different orientations and most are not aligned with their $\langle 112\rangle$ directions parallel to the growth direction.

In summary, TEM study of Si nanowire nucleation and growth indicated that thermal evaporation of $\mathrm{Si}$ powder mixed with $\mathrm{SiO}_{2}$ generated a $\mathrm{Si}$ oxide vapor phase. At the initial nucleation stage, Si oxide vapor condensed on the substrate and formed $\mathrm{Si}$ nanoprecipitates. Si nanowire nuclei consisted of a polycrystalline Si core with a high density of defects. The Si oxide vapor phase and defect structure acted as key factors which greatly enhanced the nucleation and one-dimensional growth of Si nanowires.

This work was financially supported in part by the Research Grants Council of Hong Kong and the Strategic Research Grants of the City University of Hong Kong.
*Author to whom correspondence should be addressed. Electronic address: APANNALE@ cityu.edu.hk

${ }^{1}$ R. S. Wagner and W. C. Ellis, Appl. Phys. Lett. 4, 89 (1964).

${ }^{2}$ E. I. Givargizov, J. Cryst. Growth 32, 20 (1975).

${ }^{3}$ H. I. Liu, N. I. Maluf, and R. F. W. Pease, J. Vac. Sci. Technol. B 10, 2846 (1992)

${ }^{4}$ H. Namatsu, S. Horiguchi, M. Nagase, and K. Kurihara, J. Vac. Sci. Technol. B 15, 1688 (1997).

${ }^{5}$ Y. Wada, T. Kure, T. Yoshimura, Y. Sudou, T. Kobayashi, Y. Gotou, and S. Kondo, J. Vac. Sci. Technol. B 12, 48 (1994).

${ }^{6}$ T. Ono, H. Saitoh, and M. Esashi, Appl. Phys. Lett. 70, 1852 (1997).

${ }^{7}$ R. Hasunuma, T. Komeda, H. Mukaida, and H. Tokumoto, J.
Vac. Sci. Technol. B 15, 1437 (1997).

${ }^{8}$ A. M. Morales and C. M. Lieber (unpublished).

${ }^{9}$ A. M. Morales and C. M. Lieber, Science 279, 208 (1998).

${ }^{10}$ N. Wang, Y. H. Tang, Y. F. Zhang, D. P. Yu, C. S. Lee, I. Bello, and S. T. Lee, Chem. Phys. Lett. 283, 368 (1998).

${ }^{11}$ Y. F. Zhang, Y. H. Zhang, N. Wang, D. P. Yu, C. S. Lee, I. Bello, and S. T. Lee, Appl. Phys. Lett. 72, 1835 (1998).

${ }^{12}$ N. Wang, Y. H. Tang, Y. F. Zhang, C. S. Lee, and S. T. Lee (unpublished).

${ }^{13}$ S. W. Roberts, G. J. Parker, and M. Hempstead, Opt. Mater. 6, 99 (1996).

${ }^{14}$ U. Setiowati and S. Kimura, J. Am. Ceram. Soc. 80, 757 (1997).

${ }^{15}$ G. Hass and C. D. Salzberg, J. Opt. Soc. Am. 44, 181 (1954). 